\title{
Pengaruh Rentang Suhu Distilasi Fraksinasi Terhadap Kadar Patchouli Alcohol (PA) Pada Minyak Nilam
}

\author{
Puji Lestari $^{1}$, Sarifah Nurjanah ${ }^{2}$, Efri Mardawati ${ }^{2}$ \\ 1)Widyaiswara Ahli Pertama Balai Pelatihan Pertanian Jambi, Indonesia \\ 2)Fakultas Teknologi Industri Pertanian - Universitas Padjadjaran, Jawa Barat, Indonesia \\ e-mail : lestaripuji1984@gmail.com
}

\begin{abstract}
Patchouli oil is one of the essential oil products which are Indonesia's main export commodities. Patchouli alcohol (PA) level is one indicator that determines the quality of patchouli oil. Patchouli oil is the result of the distillation of patchouli (Pogestemon cablin Benth) leaves. One way to improve the quality of patchouli oil is to isolate patchouli alcohol contained in it using the fractionation distillation method. This study aims to determine the effect of the fractionation distillation temperature range on patchouli alcohol (PA) levels. The research method used was an experimental method with descriptive analysis. This research was conducted with a range of fractionation distillation temperatures divided into 3 cuts, namely cut $1\left(230-283^{\circ} \mathrm{C}\right)$, cut $2\left(283-290^{\circ} \mathrm{C}\right)$ and cut $3\left(290-300{ }^{\circ} \mathrm{C}\right)$. The distillation process uses the B / R Instrument Spinning Band Distillation System Model 36-100 engine integrated with the computer. Observations made were patchouli alcohol (PA) levels in each fractionation distillation temperature range. Measurement of patchouli alcohol (PA) levels using GC-MS. The GC-MS test results show that there is an increase between the initial oil and after the oil is carried out by the fractionation distillation process. Initial patchouli oil had patchouli alcohol level of $25.16 \%$. The results showed that the fraction that had the highest patchouli alcohol content in cut 3 was $90.38 \%$.
\end{abstract}

Keywords: fractional distillation, patchouli oil, patchouli alcohol, temperature range

\begin{abstract}
Abstrak
Minyak nilam adalah salah satu produk minyak atsiri yang menjadi komoditi ekspor andalan Indonesia. Kadar patchouli alcohol (PA) merupakan salah satu indikator yang menentukan kualitas minyak nilam. Minyak nilam merupakan hasil penyulingan daun tanaman nilam (Pogestemon cablin Benth). Salah satu cara untuk meningkatkan mutu minyak nilam adalah dengan mengisolasi patchouli alcohol yang terkandung didalamnya dengan menggunakan metode distilasi fraksinasi. Penelitian ini bertujuan untuk mengetahui pengaruh rentang suhu distilasi fraksinasi terhadap kadar patchouli alcohol (PA). Metode penelitian yang digunakan adalah metode eksperimen dengan analisis deskriptif. Penelitian ini dilakukan dengan rentang suhu distilasi fraksinasi dibagi menjadi 3 cut yaitu cut $1\left(230-283{ }^{\circ} \mathrm{C}\right)$, cut $2(283-290$ ${ }^{\circ} \mathrm{C}$ ) dan cut $3\left(290-300{ }^{\circ} \mathrm{C}\right)$. Proses distilasi menggunakan mesin B/R Instrument Spinning Band Distillation System Model 36-100 yang terintegrasi dengan komputer. Pengamatan yang dilakukan adalah kadar patchouli alcohol (PA) pada masing-masing rentang suhu distilasi fraksinasi. Pengukuran kadar patchouli alcohol (PA) menggunakan GC-MS. Hasil uji GC-MS menunjukkan bahwa terjadi peningkatan antara minyak awal dan setelah minyak dilakukan proses distilasi fraksinasi. Minyak nilam awal memiliki kadar patchouli alcohol sebesar 25,16\%. Hasil menunjukkan bahwa fraksi yang memiliki kadar patchouli alcohol yang tertinggi pada cut 3 yaitu 90,38\%.
\end{abstract}

Kata Kunci: distilasi fraksinasi, minyak nilam, patchouli alcohol, rentang suhu

\section{PENDAHULUAN}

Minyak atsiri atau minyak eteris adalah istilah yang digunakan untuk minyak yang mudah menguap dan diperoleh dari tanaman dengan cara penylingan uap (Guenther, 1987). Karakteristik fisik minyak atsiri berupa cairan kental yang dapat disimpan pada suhu ruang dan memiliki ciri 
utama mudah menguap dan beraroma khas (Rusli, 2010). Karena itu minyak atsiri banyak digunakan sebagai bahan dasar dalam industri kimia, seperti produk wewangian (parfum), farmasi, kosmetika, pengawetan barang, dan kebutuhan dasar industri lainnya (Mangun dkk., 2012).

Minyak atsiri dihasilkan dari berbagai jenis tanaman penghasil minyak atsiri, salah satunya adalah adalah nilam. Tanaman nilam (Pogostemon patchouli atau Pogostemon cablin Benth) merupakan tanaman perdu wangi berdaun halus dan berbatang segi empat yang dapat disuling daun keringnya untuk mendapatkan minyak (patchouli alcohol) (Mangun dkk., 2012). Di Indonesia terdapat tiga jenis nilam yang dapat dibedakan menurut karakter marfologinya, kandungan patchouli alcohol, dan kualitas minyak serta ketahanan terhadap cekaman biotik dan abiotik, yaitu Pogestemon cablin Benth atau nilam aceh, Pogostemon heyneanus Benth atau nilam jawa, dan Pogostemon hortenis Becker atau nilam sabun( Amalia, 2013).

Minyak nilam adalah salah satu produk minyak atsiri terbesar yang dihasilkan oleh Indonesia dan mempunyai potensi yang cukup baik jika dibandingkan dengan jenis tanaman penghasil minyak atsiri lainnya. Salah satu keunggulan minyak nilam yang tidak dimiliki oleh minyak atsiri pada umumnya adalah mempunyai zat pengikat sehingga menyebabkan aroma wangi tidak mudah menguap. Ciri khas dari segi aroma, warna dan komponen yang terkandung di minyak nilam yang berasal dari Indonesia mempunyai kelebihan tersendiri, maka pasaran minyak nilam menjadi suatu primadona dalam kancah perdagangan minyak atsiri internasional dan minyak nilam Indonesia mempunyai aromanya sangat harum dan tahan lama (Kardinan dan Mauludi, 2004).

Indonesia saat ini sebagai penghasil minyak nilam terbesar di dunia yang mana tiap tahunnya memasok $70 \%$ hingga $90 \%$ kebutuhan dunia (Dinas Perkebunan Jawa Timur, 2012). Industri minyak nilam merupakan penyumbang devisa terbesar dari berbagai minyak atsiri yang diproduksi di Indonesia. Hal ini dapat dilihat dari setiap tahun lebih dari $45 \%$ devisa negara dihasilkan dari minyak atsiri yang berasal dari nilam (Santoso, 1990). Sebagian besar minyak nilam yang diekspor ini dihasilkan oleh petani kecil atau penyuling skala kecil di berbagai wilayah di Indonesia.

Dominasi Indonesia di dalam perdagangan minyak nilam di dunia ini tidak terlepas dari besarnya luas areal tanam dan peningkatan/perbaikan dalam hal teknologi budidaya. Menurut Ditjenbun (2011), nilam yang diusahakan oleh petani seluas 24,718 ha dengan daerah penyebaran di beberapa provinsi yaitu Aceh, Sumatera Utara, Sumatera Barat, Riau, Kepulauan Riau, Sumatera Selatan, Bangka Belitung, Jawa Barat, Jawa Tengah, Jawa Timur, Bali, Nusa Tenggara Timur, Kalimantan Selatan, Kalimantan Timur, Sulawesi Selatan dan Sulawesi Tengah.

Minyak nilam merupakan bahan baku penting dalam industri parfum dan kosmetik di antaranya untuk pembuatan sabun, pasta gigi, deodorant, lation, kebutuhan industri makanan (sebagai penambah rasa atau essence), kebutuhan farmasi (sebagai antiserangga, anti-inflamasi, antidepresi, 
antiflogistik, dekongestan, serta antiradang), sebagai aromaterapi dan kebutuhan industri lainnya (Nugroho, 2008).

Kadar patchouli alcohol adalah salah satu indikator yang sangat menentukan mutu, kualitas dan harga minyak nilam dengan kadarnya tidak boleh kurang 30\%. Semakin tinggi kadar patchouli alcohol dalam minyak nilam, maka mutu minyak nilam semakin baik (Annisa, 2013). Petani nilam di Indonesia pada umumnya hanya bisa menghasilkan minyak nilam dengan kadar patchouli alcohol sebesar 26-28\% (Isfaroiny dan Mitarlis, 2005). Ini disebabkan oleh banyak hal antara lain penanganan pascapanen bahan sebelum disuling belum baik, proses penyulingan belum optimal (masih dilakukan dengan cara dan alat yang sederhana, karena masih rendahnya kadar patchouli alcohol ini menyebabkan rendahnya harga dan tidak bisa memenuhi standar pasar internasional (Aisyah dkk., 2010).

Pada skala pabrik penyulingan dengan menggunakan alat suling berbahan baja anti karat ternyata mampu menghasilkan minyak nilam dengan patchouli alcohol 3135\% (Trubus, 1998). Kandungan patchouli alcohol dalam minyak nilam dapat ditingkatkan maksimal hingga lebih dari 4050\% (Annisa, 2013).

Menurut Ma'mun dan Maryadhi (2008), patchouli alcohol dalam bentuk murni sebagai standar atau bahan acuan (reference material) pada pengujian mutu minyak nilam belum tersedia. Hal ini karena senyawa authentic patchouli alcohol murni masih sulit untuk diperoleh. Pembuatan bahan standar patchouli alcohol yang terkandung dalam minyak minyak nilam dapat dilakukan dengan cara mengisolasi patchouli alcohol. Salah satu metode yang digunakan adalah dengan distilasi fraksinasi.

Sebelumnya, telah cukup banyak penelitian mengenai distilasi fraksinasi vakum sebagai upaya untuk meningkatkan kadar patchouli alcohol pada destilat hasil distilasi fraksinasi. Dari hasil penelitian yang dilakukan oleh Yudistira dan Sufianti (2009), metode distilasi fraksinasi adalah metode terbaik dalam memisahkan kandungan patchouli alcohol dibandingkan dengan metode aerasi dan metode distilasi uap dengan kadar patchouli alcohol sebesar 76,57\%. Menurut Guenther (1987), distilasi fraksinasi suatu proses pemisahan komponen kimia yang terdapat pada minyak atsiri berdasarkan titik didih dan berat molekulnya, dengan menggunakan metode distilasi fraksinasi, komponen senyawa patchouli alcohol dengan titik didih dan berat molekulnya dapat diisolasi.

\section{METODE}

Penelitian dilakukan di Laboratorium Pasca Panen dan Teknologi Proses Fakultas Teknnologi Industri Pertanian Universitas Padjadjaran.

Metode yang digunkaan pada penelitian ini adalah metode experimental. Data di analisis deskriptif. Perlakuan Penelitian yang dilakukan adalah menggunakan rentang suhu distilasi fraksinasi di bagi menjadi 3 cut yaitu cut 1 $\left(230-283^{\circ} \mathrm{C}\right)$, cut $2\left(283-290^{\circ} \mathrm{C}\right)$ dan cut 3 $\left(290-300{ }^{\circ} \mathrm{C}\right)$

\subsection{Tahapan Penelitian}

Proses distilasi fraksinasi dilakukan dengan menggunkan $B / R$ Instrument- 
Spinnin System Model 36-100. Jumlah sampel sebanyak $200 \mathrm{ml}$. Minyak kemudian yang dimasukkan ke dalam labu didih yang terhubung dengan kolam fraksinasi sepanjang $90 \mathrm{~cm}$. Sampel pada labu didih dipanaskan dengan mantel pemanas. Selanjutnya menyalakan condenser, dimana sistem harus dialiri dengan air untuk mengondensasikan fase gas pada bagian distilat. Proses distilasi fraksinasi berlangsung dalam keadaan vakum yang dikondisikan oleh pompa vakum. Kemudian pada program control diatur kondisi proses yang akan digunakan. Kondisi proses yang dikontrol. Setelah kondisi proses diatur sesuai dengan cara distilasi, selanjutnya menyalakan proses istilasi fraksinasi.

Pada proses penelitian ini menggunakan rentang waktu suhu distilasi yaitu cut $1\left(230-283^{\circ} \mathrm{C}\right)$, cut $2\left(283-290{ }^{\circ} \mathrm{C}\right)$ dan cut 3 (290-300 $\left.{ }^{\circ} \mathrm{C}\right)$. Pada masingmasing cut dilakukan uji kadar patchouli alcohol (PA). Tabel Kondisi perlakuan secara lengkap disajikan pada Tabel 1 untuk masing-masing perlakuan.

Tabel 1 Kondisi Proses Destilasi Fraksinasi

\begin{tabular}{ccc}
\hline Variables & $\begin{array}{l}\text { Nilai yang } \\
\text { digunakan }\end{array}$ & Satuan \\
\hline Cut 1 & $230-283$ & ${ }^{0} \mathrm{C}$ \\
Cut 2 & $283-290$ & ${ }^{\circ} \mathrm{C}$ \\
Cut 3 & $290-300$ & ${ }^{\circ} \mathrm{C}$ \\
\hline
\end{tabular}

Minyak nilam awal dan minyak nilam hasil destilasi fraksanasi pada masingmasing cut dianalisis kadar patchouli alcohol (PA).

\section{HASIL DAN PEMBAHASAN}

Proses fraksinasi adalah proses permurnian zat/senyawa yang digunakan untuk memisahkan komponen dari campuran berdasarkan titik didih. Proses distilasi fraksinasi nilam dilakukan dengan mengunakan mesin $B / R$ Instrument Spinning Band Distillation System Model 36-100 yang terintegrasi dengan komputer. Jumlah bahan baku minyak nilam pada setiap proses distilasi fraksinasi adalah 150 $\mathrm{mL}$, kemudian distilat hasil fraksinasi selanjutnya dilakukan uji kemurnian menggunakan GC-MS untuk mengetahui besarnya kandungan patchouli alcohol. Pada proses distilasi fraksinasi, suhu yang digunakan dalam proses distilasi ini dibagi menjadi tiga rentang suhu (tiga fraksi/tiga cut) yaitu cut 1 dengan rentang suhu 230 ${ }^{\circ} \mathrm{C}-283{ }^{\circ} \mathrm{C}$, cut 2 dengan rentang suhu 283 ${ }^{\circ} \mathrm{C}-290{ }^{\circ} \mathrm{C}$, dan cut 3 dengan suhu $290{ }^{\circ} \mathrm{C}$ $300{ }^{\circ} \mathrm{C}$. Hasil uji menggunakan GC-MS (GasChoromatagraphyMassSpectromery)m enunjukkan bahwa terjadi peningkatan antara minyak awal dan setelah minyak dilakukan proses distilasi fraksinasi. Minyak nilam awal memiliki kadar patchouli alcohol sebesar 25,16\%. Peningkatan kadar patchouli alcohol setelah dilakukan proses distilasi dapat dilihat pada Gambar 1.

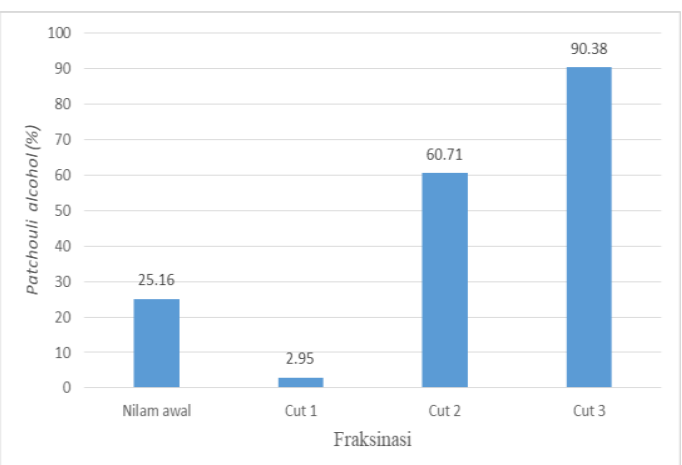

Gambar 1. Hasil Distilasi Minyak Nilam Pada tiap cut

Berdasarkan hasil uji GC-MS, Bahwa fraksi yang memiliki kadar patchouli alcohol yang tinggi terdapat pada cut 3 yaitu 90,38 \%. Selain itu, hasil uji GC-MS menunjukkan bahwa komponen terbesar juga terdapat 
pada cut 2 yaitu $60,71 \%$. Hal ini disebabkan rentang suhu yang digunakan yaitu $283^{\circ} \mathrm{C}$ $290^{\circ} \mathrm{C}$ (Guenther, 1949).

Kualitas minyak ditentukan oleh sifatkimia minyak tersebut dan sifat kimia yang paling menentukan mutu minyak nilam adalah kadar patchouli alcohol (PA) yang terkandung dalam minyak nilam (Anissa, 2013). Menurut Aisyah, dkk (2008), patchouli alcohol merupakan senyawa yang menentukan bau minyak dan merupakan komponen yang tersebar dalam minyak nilam Sehingga dapat dikatakan semakin tinggi kadar patchouli alcohol dalam minyak, maka mutu minyak nilam semakin baik.

Bedasarkan hasil pengujian yang telah dilakukan menggunakan GC-MS, diketahui kadar patchouli alcohol tertinggi pada cut 3 dan terendah pada cut 1 . Tinggi rendahnya kadar patchouli alcohol dalam cut yang dihasilkan, dipengaruhi oleh rentang kadar patchouli alcohol pada cut 1 untuk menandakan bahwa rentang suhu yang digunakan pada cut 1 tersebut yaitu $230^{\circ} \mathrm{C}$ - $283{ }^{\circ} \mathrm{C}$, belum mencapai titik didih patchouli alcohol sehingga patchouli alcohol tiduk ikut terdistilasi pada cut 1.

Dilihat pada cut 3 dengan rentang suhu $\left(290-300^{\circ} \mathrm{C}\right)$, menghasilkan kadar patchouli alcohol berada pada rentang suhu cut 3. Menurut Guenther (1987), fraksinasi minyak atsiri adalah pemisahan minyak atsiri menjadi beberapa fraksinasi berdasarkan perbedaan titik didihnya. Titik didihnya dapat didefinisikan sebagai suhu pada tekanan atmosfer atau pada tekanan tertentu lainnya, dimana cairan akan berubah menjadi uap atau suhu pada saat tekanan uap dari cairan tersebut sama dengan tekanan gas atau uap yang berada disekitarnya. Jika dilakukan proses penyulingan pada tekanan atmosfer maka tekanan uap akan tersebut akan sama dengan tekanan air raksa dalam kolom setinggi $760 \mathrm{mmHg}$. Berkurangnya tekanan pada ruangan dia tas cairan akan menurunkan titik didih, dan sebaiknya peningkatan tekanan di atas permukaan cairan akan menaikkan titik didih cairan tersebut. Patchouli alcohol diketahui memiliki titik didih sebesar $150-160{ }^{\circ} \mathrm{C}$ pada $8 \mathrm{mmHg}$ (Sudibyo dan Susanti, 2011) dan $280,73{ }^{\circ} \mathrm{C}$ pada tekanan atmosfir (Sariadi, 2012).

Dengan melakukan distilasi fraksinasi, senyawa patchouli alcohol dengan titik didih dan berat molekul tertentu dapat diisolasi dari minyak nilam. Distilasi fraksinasi umumnya digunakan di beberapa industri untuk pemurnian produk dengan kisaran fraksi yang lebar dan memperbaiki bahan mentah supaya dapat digunakan kembali (Silviana dan Purbasari, 2006). Faktor yang paling penting dalam melakukan distilasi fraksinasi yang efektif adalah kontak anatara fase cair dan uap di dalam kolom, menjadi gradient temperatur pada kolom panjang, serta perbedaan titik didih dari komponen yang terdapat pada campuran (Gilbert dan Renshaw, 2011). Sedangkan variable yang mempengaruhi proses distilasi fraksinasi adalah run type, tekanan, initial heat, euqilibration time, jumlah cut atau fraksi suhu awal dan akhir cut, heat rate tiap cut dan suhu kondensor tiap cut.

Adapun hasil minyak nilam distilasi pada masing-masing cut disajikan pada Gambar 2. 


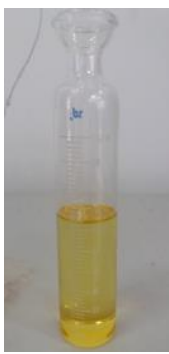

Cut 1

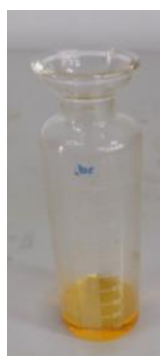

Cut 2

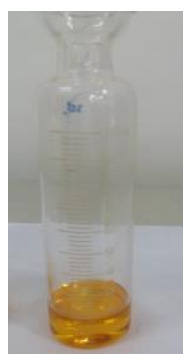

Cut 3
Gambar 2. Hasil Distilasi Minyak Nilam Pada tiap cut

Teknik distilasi fraksinasi yang akan digunakan pada penelitian ini adalah teknik distilasi fraksinasi vakum. Hal ini didasari oleh pernyataan Guenther (1987), dimana sebaiknya minyak atsiri tidak difraksinasi pada terkanan atmosfir, tetapi dalam keadaan vakum karena tekanan atmosfir dan suhu tinggi dapat mengakibatkan dekomposisi dan resinifikasi, sehingga distilat mempunyai bau dan sifat fisik-kimia yang berbeda dengan minyak murni. Selain itu, teknik distilasi fraksinasi vakum dipilih untuk digunakan karena menurut Irawan (2010), beberapa bahan organik tidak dapat didistilasi secara memuaskan pada tekanan atmosfer sebab akan mengalami penguraian atau dekomposisi sempurna sebelum titik didih normal tercapai, sehingga dengan mengurangi tekanan eksternal 0,1-30 $\mathrm{mmHg}$, titik didih dapat diturunkan dan distilasi dapat berlangsung tanpa mengakibatkan terjadinya dekomposisi. Salah satu penelitian terdahulu mengenai upaya peningkatan kadar patchouli alcohol pada minyak nilam menggunakan distilasi fraksinasi vakum adalah penelitian yang dilakukan oleh Yudistira dan Sufianti (2009).

Kandungan patchouli alcohol yang rendah menandakan bahwa minyak nilam awal memiliki kualitas yang rendah sehingga diperlukan suatu upaya untuk meningkatkan kadar patchouli alcohol salah satunya dengan distilasi fraksinasi.

\section{KESIMPULAN DAN SARAN}

\subsection{Kesimpulan}

Proses distilasi fraksinasi dengan kondisi operasi yang sesuai dapat meningkatkan kadar patchouli alcohol pada minyak nilam pada tiap cut yang dihasilkan.

\subsection{Saran}

Disarankan perlu dilakukan analisa lanjutan mengenai komponen lain selain patchouli alcohol yang terkandung dalam minyak nilam hasil distilasi fraksinasi dengan menggunakan uji GC-MS.

\section{UCAPAN TERIMA KASIH}

Ucapan terima kasih kepada universitas Pajadjaran Bandung Program Studi Teknologi Agroindustri dan ucapan terima Kasih Kepada Dr. Ir Sarifah Nurjanah, M.App.Sc dan Dr. Efri Mardawati S.TP.,M.T yang telah banyak memberikan konstribusi dalam penulisan jurnal ini.

\section{DAFTAR PUSTAKA}

Aisyah, S. dan Masril, C. (2010). Pemisahan Senyawa Patchouli Alcohol dari Minyak Nilam dengan Cara Distilasi Fraksinasi. Jurnal Teknik. Industri.Pertanian, Vol. 21 (2), 89-93. Diunduh dari journal.ipb.ac.id/index.php/jurnaltin/arti cle/view/4788/3256. Diakses pada 9 September 2017.

Annisa, Y. (2013). Peningkatan Kadar Patchouli alkohol Minyak Nilam dengan Metode Distilasi Fraksinasi Vakum. Universitas Syiah Kuala. BandaAceh.SkripsiTerdapatpadahttp:/ /etd.Unsyiah.ac.id/index.php?show_d etail\& id-1089. Diakses pada 16 juli 2017.

Amalia. (2013). Karakteristik Tanaman Nilam Di Indonesia. Balai Penelitian 
Tanaman Rempah dan Obat: Monograp Nilam (Patchouli). Terdapat pada

http://balittro.litbang.pertanian.go.id/in $\mathrm{d} /$ index.php/en/publikasi/terbitankhusus/233-monograp-nilam. Diakses pada 21 Maret 2017.

Dinas Perkebunan Provinsi Jawa Timur. (2012). Teknologi Pengolahan Nilam. Surabaya.

Direktorat Jenderal Perkebunan. (2011). Nilam. Statistik Perkebunan Tahun 2009-2011.

Guenther, E. (1987). Minyak Atsiri Jilid I. Penerjemah S. Ketaren dan R Mulyono. Ui Press. Jakarta.

Irawan, B. (2010). Peningkatan Mutu Minyak Nilam dengan Ekstraksi dan Distilasi Pada Berbagai Komposisi Pelarut. Tesis. Magister Teknik Kimia Universitas Diponegoro, Semarang.

Isfaroiny, $\mathrm{R}$ dan Mitarlis. (2005). Peningkatan Kadar Patchouli Alkohol Pada Minyak Nilam (Pogostemon Cablin Benth) dengan Metode Distilasi Fraksinasi Vakum. Berk. Penel. Hayati : 10 (123-127). Fakultas Matematika dan IImu Pengetahuan Alam. Universitas Negeri Surabaya. Surabaya.

Kardinan, A. dan Mauludi, L. (2004). Nilam; Tanaman Beraroma Wangi untuk Industri Parfum \& Kosmetik. AgroMedia Pustaka. Tangerang.

Ma'mun dan Maryadhi, A. (2008). Isolasi Patchouli Alkohol Dari Minyak Nilam Untuk Bahan Referensi Pengujian Dalam Analisis Mutu. Terdapat pada http://balittro.litbang.pertanian.go.id/in d/images/stories/Buletin/20081/9nilam.pdf. Diakses pada 17 Januari 2017.

Mangun, H. M. S., Waluyo, H., dan Purnama S., A. (2012). Nilam. Penebar Swadaya. Jakarta.

Nugroho, A. (2008). Business Plan. Fakultas Ekonomi. Universitas Indonesia. Jakarta.

Rusli, R. (2016). Sistem Kristal dan Kisi Bravais. Terdapat Pada http://rolanrusli.com/sistem-kristaldan-kisi-bravais. Diakses pada 16 September 2017.

Santoso, H. R. (1990). Bertanam Nilam. Kanisius. Yogyakarta.

Sariadi. (2012). Pemurnian Minyak Nilam dengan Proses Adsorpsi Menggunakan Bentonit. Jurnal
Teknologi, Vol. 12, No. 2. Teknik Kimia Politeknik Negeri Lhokseumawe. Aceh.

Silviana dan Purbasari. (2006). Studi Awal Deterpenisasi Minyak Nilam dengan Teknologi Redistilasi Vakum. Terdapat pada http://repository.usu.ac.id/bitstream/12 3456789/26612/1/Reference.pdf. Diakses pada 17 Januari 2017.

Sudibyo A. dan Susanti I. (2011). Studi Pemanfaatan Air Bittern Sebagai Suplemen dan Pengawetan Produk Pangan. Balai Besar Industri Agro (BBIA). Bogor.

Trubus. (1998). Budidaya Nilam di Purbalingga. PT. Niaga Swadaya. Jakarta. 